\title{
Developing Sustainable and Flexible Rural-Urban Connectivity through Complementary Mobility Services
}

\author{
Lisa Bauchinger ${ }^{1}{ }^{\circ}$, Anna Reichenberger ${ }^{2} \oplus$, Bryonny Goodwin-Hawkins ${ }^{3}{ }^{\oplus}$, Jurij Kobal ${ }^{4}$, Mojca Hrabar ${ }^{4}\left({ }^{\circ}\right.$ and \\ Theresia Oedl-Wieser ${ }^{1, *(1)}$ \\ 1 Federal Institute of Agricultural Economics, Rural and Mountain Research, 1030 Vienna, Austria; \\ lisa.bauchinger@bab.gv.at \\ 2 Regional Management of the Metropolitan Area of Styria, 8010 Graz, Austria; \\ reichenberger@zentralraum-stmk.at \\ 3 Countryside and Community Research Institute, University of Gloucestershire, Cheltenham GL50 4AZ, UK \\ bgoodwinhawkins@glos.ac.uk \\ 4 Oikos, Sustainable development Inc., 1241 Kamnik, Slovenia; jurij.kobal@oikos.si (J.K.); \\ mojca.hrabar@oikos.si (M.H.) \\ * Correspondence: theresia.oedl-wieser@bab.gv.at; Tel.: +43-1-71100-637518
}

Citation: Bauchinger, L.;

Reichenberger, A.

Goodwin-Hawkins, B.; Kobal, J.;

Hrabar, M.; Oedl-Wieser, T.

Developing Sustainable and Flexible

Rural-Urban Connectivity through

Complementary Mobility Services.

Sustainability 2021, 13, 1280.

https://doi.org/10.3390/su13031280

Academic Editor: David Gibbs

Received: 10 December 2020

Accepted: 21 January 2021

Published: 26 January 2021

Publisher's Note: MDPI stays neutral with regard to jurisdictional claims in published maps and institutional affiliations.

Copyright: (c) 2021 by the authors Licensee MDPI, Basel, Switzerland. This article is an open access article distributed under the terms and conditions of the Creative Commons Attribution (CC BY) license (https:/ / creativecommons.org/licenses/by/ $4.0 /)$.

\begin{abstract}
Transport can play a key role in mitigating climate change, through reducing traffic, emissions and dependency on private vehicles. Transport is also crucial to connect remote areas to central or urban areas. Yet, sustainable and flexible transport is among the greatest challenges for rural areas and rural-urban regions. Innovative transport concepts and approaches are urgently needed to foster sustainable and integrated regional development. This article addresses challenges of sustainability, accessibility, and connectivity through examining complementary systems to existing public transport, including demand-responsive transport and multimodal mobility. We draw upon case studies from the Metropolitan Area of Styria, Ljubljana Urban Region and rural Wales (GUSTmobil, REGIOtim, EURBAN, Bicikelj, Bwcabus, Grass Routes). In-depth analysis through a mixed-methods case study design captures the complexity behind these chosen examples, which form a basis for analysing the effects of services on accessibility for different groups, connectivity to public transport and usability as a "first and last mile" feeder. We further explore the weaknesses of complementary transport systems, including legal, organisational and financial barriers, and offer potential solutions to structure and communicate complementary transport systems to improve access and use. Looking ahead, we use the case studies to anticipate innovative, sustainable "mobility as a service" (MaaS) solutions within and between urban and rural areas and consider how future public policy orientations and arrangements can enable positive change. A main concern of our article and the contribution to scientific literature is through exploring the benefit of well-established multi-level governance arrangements when introducing smaller-scale mobility solutions to improve rural-urban accessibility. It becomes clear that not a one-size-fits-all model but placed-based and tailored approaches lead to successful and sustainable concepts.
\end{abstract}

Keywords: public transport; mobility; rural-urban; sustainable transport; multimodal mobility; micro-public transport; complementary mobility

\section{Introduction}

While it is axiomatic that achieving sustainable transport goals must entail a modal shift [1], it is also evident that modern car dependency is a self-reinforcing dynamic [2]. Within the EU, over two thirds of passenger journeys are made by car [3]. Private cars continue to attract negative attention amongst sustainable transport proponents for the high emissions of conventional engine technologies [4], urban congestion patterns [5], poor public health outcomes [6], and the broader social and spatial consequences of 'automobility' [7]. Making transport more sustainable has rightly become a key European 
policy goal. The recent European Green Deal states that, 'Achieving sustainable transport means putting users first and providing them with more affordable, accessible, healthier and cleaner alternatives to their current mobility habits' [8]. These are ambitions with considerable implications for rural-urban connectivity.

Many European cities have established public transport networks, and recent years have witnessed further multimodal mobility innovations [4,9], alongside planning interventions to reduce congestion and promote healthier active travel [4,6]. Just as sustainable transport has climbed the urban agenda [10], long-term processes of rural marginalisation $[11,12]$ have entrenched both the necessity for travel over longer distances and made transport accessibility an emblematic rural problem [13]. This has especially disproportionate effects on certain groups, such as persons without a private car or driving licence. $[14,15]$. Reducing the risk of social exclusion, however, tends to make car ownership a necessity $[2,16]$. These contrasting rural and urban transport conditions are, equally, inter-related. After all, transport systems connect rural and urban areas, and most functional regions combine both geographies in patterns of daily life, work and leisure. This article places passenger transport in a rural-urban perspective, through engaging with the practical problem of facilitating the modal shift from private car usage to (micro-)public transport, not only to reduce emissions [4] but, and most importantly, to improve accessibility and prevent social exclusion [16-18]. Poor access to services results in socio-economic and demographic challenges and is, therefore, greatly linked to the quality of life of a region [13].

We recognise, however, that public transport requires infrastructures and investments that are at times inefficiently utilised and, furthermore, face physical and financial limits. In addition, existing public transport systems suffer from missing links, notably the 'first and last mile' [19], and poor cooperation between providers that cannot be remedied by extension alone. Our argument therefore is neither for simply more infrastructure nor more public transport, but for solutions to facilitate the modal shift towards (micro-)public transport that are flexible, cost-effective and connect the small-scale to wider rural-urban flows. We conceptualise such solutions through multimodal complementary mobility. Here, we refer to implementations that complement existing (public) transport systems and infrastructures. There are numerous good examples of multimodal complementary mobility systems. However, most concepts implemented in rural areas are rarely profitable due to low density and low customer numbers. In many cases, these solutions are shortterm projects financed by subsidies and terminated shortly after the funding period due to limited financial resources. Therefore, we investigate multimodal complementary mobility through two research questions:

1. What are the promoting and inhibiting factors for multimodal complementary transport systems?

2. How can the operation of multimodal complementary systems be sustained over a longer-term perspective?

The article proceeds as follows. We begin by reviewing the literature to demonstrate the rural-urban challenges for sustainable and accessible transport. This review is used to outline the conceptual framework of multimodality and complementary transport. Following an explanation of methodology, we present the practical case studies from the Metropolitan Area of Styria (Austria), Ljubljana Urban Region (Slovenia) and rural Wales (UK). Further, we conduct an analysis of the implemented mobility solutions in the case studies. In the discussion section, we then assess the effects of complementary interventions on accessibility and connectivity, as well as on our criteria defined in the methodology section, including legal framework and financial barriers. We look upon the different governance arrangements in the case study regions, as well as the innovative concept of 'Mobility as a Service' (MaaS), as an opportunity for rural-urban connectivity, considering how future policy mechanisms can enable positive, sustainable change. Finally, we conclude with lessons learned and opportunities for durable implementation strategies. 


\section{Literature Review}

Mobility is an ambivalent phenomenon [9], which has enabled positive economic and social benefits while simultaneously producing new problems and externalised costs [1]. The sustainability challenges of automotive transport, in particular, began to be recognised in the 1970s [5], and are now widely reflected in policy [8,10]. The social, economic and environmental dimensions of sustainability undergird most contemporary approaches [5]. Vreeker and Nijkamp [20] are representative in defining sustainable transport through objectives for: (1) Economic efficiency, including improved regional connectivity; (2) social equity, including improved access to overcome socio-economic and spatial marginalisation; and (3) environmental sustainability, including reduced pollution, congestion and noise.

While sustainability has become an imperative for the urban agenda [10], accessibility endures as a rural impediment [13]. In contrast to urban density, rural populations are typically small and dispersed, and rural geographies may be remote or rugged. Providing public transport is challenging in this context $[13,21]$. Infrastructures in many rural regions are underdeveloped or outdated [12], and costs for transport over long distances are high [22]. As limited critical mass provides few economies of scale [14], there are disincentives to innovation in rural public transport [17] and market failure can occur [13]. Market and public provision cutbacks alike create a vicious cycle whereby fewer routes lead to fewer passengers, and in turn, to further reductions [11,14]. As a result, many rural residents necessarily depend on private cars [21,22], and there is evidence that emissions from transport are higher per capita in rural and peri-urban areas [2]. However, car-dependency leads to social injustices as the access to mobility services is enormously limited for those population groups without driving licences or a private car. This affects children and young people, the elderly, people with disabilities and members of low-income households [16,18].

Poor access to transport is known to increase the risk of social exclusion, which means 'the lack or denial of resources, rights, goods and services, and the inability to participate in the normal relationships and activities, available to the majority of people in a society' [23]. Social exclusion emerges in the interaction between individual and structural factors [24], and the risk can become acute for disadvantaged groups $[2,24]$ and in marginalised geographies [13]. At fundamental issue here is not access to transport per se, but rather the social and economic consequences [24]. As a result, there remains 'a latent tension between ensuring fair levels of access [ ... ] and achieving a rapid reduction in transport emissions' [2]. This tension has particular implications for rural-urban connectivity. Banister [25] has influentially argued for four transitions towards sustainable transport: (i) Modal shift; (ii) planning interventions, such as compact cities; (iii) new technologies to increase transport efficiency; and (iv) reducing the need to travel.

Again, it is certainly possible to envisage 'cities of such quality and at a suitable scale that people would not need to have a car' [4], but there are far greater difficulties in imagining an equivalent for dispersed rural areas. As urban issues tend to dominate sustainable transport research [26] and policy [10], there is a risk of overbalanced investments and initiatives unintentionally displacing car dependence from the city to the country. Indeed, as sustainable transport becomes part of a desirable urban lifestyle [4], worsening rural public transport is simultaneously making it more difficult to reconcile reducing emissions while maintaining acceptable standards of living [2]. More so, the ongoing expansion of functional urban areas, which centralise employment and services in cities, also intensify traffic flows [5] and grow travel distances [4]. If car dependency is being displaced to the country, then traffic is flowing back to the city. As this suggests, the rural and urban challenges for sustainable, accessible transport are at once distinct and inter-related. While urban areas mostly focus on reducing emissions and the total number of cars, the aim in rural areas is to improve accessibility [27], which has become increasingly important for transport planning [28]. Preston and Rajé [29] describe a basic level of accessibility as 'ease of reaching'. This can be further broken down into: (1) The accessibility of destinations; and (2) the capability of people to access services [22]. As these factors are interdependent [22] 
and determined by a range of influences, from infrastructures to individuals, accessibility is always relative [29]. Further, accessibility as subjectively perceived by users may differ from accessibility as objectively measured by planners [28]. The decisive factor is that walking is most likely to be chosen for short distances up to one kilometre or $15 \mathrm{~min}$. The major disadvantage of public transport in rural areas is that the stations are not located directly at the actual starting or ending point of individual journeys. Opportunities or restrictions to travel this 'first or last mile' are crucial for a high acceptance of public transport. Especially in rural areas and regions with dispersed population, this speaks for the expansion of demand-responsive services [30]. However, in order to achieve a modal shift towards alternative and flexible modes of transport, accessibility must be improved and behaviour change is vital [4]. Push measures for instigating behaviour change involve interventions to discourage private car use, such as parking costs. Pull measures, however, include improving the quality and attractiveness of flexible, micro-public and public transport, as well as cycling and walking infrastructure and promoting sharing concepts [1]. A study conducted by the Bundesverband CarSharing e.V. [31], in which different carsharing user groups in four German cities were surveyed, shows that the car ownership among users of station-based and combined carsharing models decreased by around 65\% compared to 12 months before they first joined carsharing. Reasons for this result were low utilisation costs, high convenience of use, good vehicle availability and fast accessibility of booked vehicles. Another key issue of managing demand is the promotion, communication and any tariff support of such systems to guarantee high utilisation rates [32]. Brake et al. [33] emphasise the importance of awareness raising, when introducing and operating a new form of public transport service. Especially, flexible services need to be clearly recognisable and visible to the end user. Marketing measures include next to a distinctive branding, the promotion of the service to the local stakeholders and the general public. Communicating the benefits, the timetable and the tariff system are crucial measures to raise the acceptance and utilisation rate of the new service.

This section has outlined the considerable challenges posed by providing sustainable, accessible transport to support modal shift and foster rural-urban connectivity. It is easy to simply advocate for more public transport—a response that has been critiqued [29]. In reality, the costs and infrastructures required to provide traditional models of public transport over large rural-urban spaces are prohibitive. In the following chapter, we will present the scope of the paper and define necessary terms. At the same time, we will give an insight into the state of the art in the field of innovative mobility concepts.

\section{Conceptual Framework}

We focus in this section on the current and future opportunities for small-scale mobility solutions and look particularly at those that can promote sustainability and provide accessibility by 'filling the gaps' in existing public transport systems. Some such solutions must be able to operate at a scale that is local enough to cover the 'first and last mile' [34]; others have to be flexible enough to enable longer-distance rural-urban connectivity. To this end, we focus on the concept of multimodal 'complementary mobility' services with demand-responsive or flexible characteristics that support rural and rural-urban connection. We specifically explore micro-public transport services and shared mobility services. In Figure 1, the different categories of existing small-scale concepts are illustrated.

Multimodal mobility involves using more than one mode of transport along different routes, or combining modes within a route [34]. In a classic multimodal form, different modes of transport are used for different journeys, such as a bicycle for short distances, a bus for shopping trips, and a train for daily commuting. In the intermodal form, different modes are integrated into a single journey, such as a home-to-work journey involving a shared car to the train station, a train to the city, and a bicycle to the office. The ability to use many different means of transport is intended to enable each individual to achieve optimum mobility [34]. Multimodal mobility is part of a trend in which 'the traditional contrast between collective and individual transport solutions is gradually blurring' [35] as 
new alternatives to public and private transport open up alongside established systems and infrastructures. Examples include 'complementary [...] as well as flexible' transport, dynamic car- and ridesharing systems, and peer-to-peer services [35].

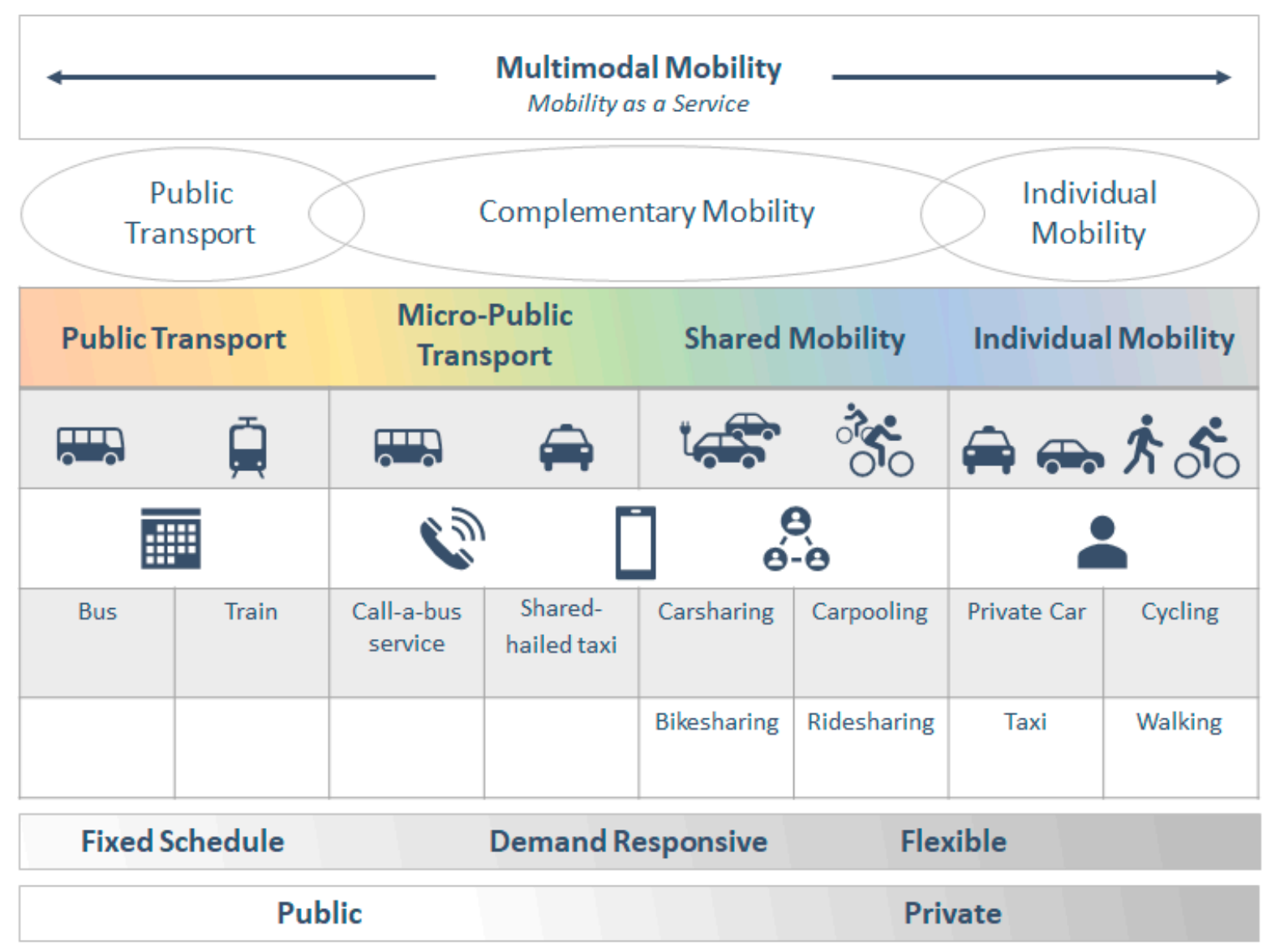

Figure 1. Mobility concepts and services. (C) Reichenberger, 2021.

By Complementary mobility, we refer to forms of transport which cannot alone satisfy an individual's complete mobility needs, but bridge gaps as a complement to other forms of mobility. Preferably, complementary mobility services interface with the existing public transport systems and infrastructures that form the backbone of multimodal mobility. Additionally, multiple complementary services with demand-responsive or flexible characteristics can interact with each other. Many modes of transport and transport delivery models can have a complementary function, but they need not necessarily have this function at all times, nor for all users. A form of transport becomes complementary when it: (1) Complements existing (public) transport systems and/or infrastructures; (2) enables multimodal mobility; and (3) offers convenience, flexibility and integration for users. There is hence no single model for complementary mobility, but a variety of ways in which it may be achieved, including: Adapting part of an existing system; extending an existing route, area or time; and connecting with longer-distance services. In this article, we focus especially on micro-public transport systems and shared mobility.

Micro-Public Transport Systems are still defined as public transport, but are demandresponsive and have greater flexibility than regular, line-bound services [36]. Demandresponsive transport (DRT) is 'a user-oriented form of passenger transport characterised by flexible routes and smaller vehicles operating in shared-ride mode between pick-up and drop-off locations according to passengers' needs' [37]. Service operation typically only takes place if there is at least one active request for a journey [38]. DRT presents an alternative to fixed-route transit, which is tied to fixed pick-up and drop-off locations and a rigid schedule. While fixed-route transit is more cost-efficient if the occupancy rate is 
high, services can fall victim to low demand in rural and sparsely populated areas [39]. When passenger demand is low and dispersed, target-oriented solutions are crucial in order to meet customer demands [40]. DRT was first introduced via dial-a-ride services to provide mobility options for older people and people with disabilities. In the last two decades, DRT services have gained a broader audience with opportunities increased by information and communication technology (ICT). While initial DRT implementations lacked flexibility due to the need for advanced booking, intelligent software systems can now match supply and demand effectively, enabling travellers to request real-time rides [41-43]. Examples include shared taxis and 'call-a-bus' services, which provide first and last mile feeder connections to public transport interchanges or direct transport to regional service centres on low-demand routes. These services can provide mobility in accordance with passenger needs and present a feasible response to gaps in existing public transport systems [34]. However, on-demand systems are, in general, more cost-intensive to deploy [39]. As a consequence, these systems are often economically not profitable and are therefore dependent on alternative financing systems. These include financing through public private partnerships and public subsidies [44].

Shared Mobility is a further step towards complementing existing services to enable different access needs (such as time, distance or user preference). It is part of the growing Sharing Economy, and involves the organised sharing of mobility services and vehicles [42,45]. Many shared mobility services are organised via a contract between operator and user, enabling provided vehicles (commonly e-cars, bicycles or scooters) or infrastructures, such as parking spaces, to be used independently. Depending on the system, vehicles are either bound to fixed stations or freely available in a defined area [46]. A high density and a well-balanced distribution of vehicles at key locations within an occupancy area are crucial for systems bound to fixed stations in order to guarantee a high utilisation rate [47]. Although sharing systems are predominantly found in urban areas, it has the potential to enable highly flexible individual multimodal mobility, as well as in low-density regions, by offering both an alternative to private car ownership and a complement to public transport [46]. Increasing demand for and implementations of flexible DRT and shared mobility concepts, that can complement public and individual transport, represent a shift from a rigid focus on motorised individual transport to multimodal mobility behaviour and towards the concept of Mobility-as-a-Service (MaaS) [48].

MaaS is an approach in which different transport services are technologically linked to each other and integrated via a single platform offering on-demand services to users. The aim is to provide users with a single source for routing information and streamlined booking and payment options to enable an optimal multimodal combination adapted to individual travel requirements. In other words, MaaS brings together single pieces of a puzzle to form a comprehensive mobility picture [35]. In the following sections, we present case studies to illustrate these concepts in operation.

\section{Methods and Choice of Cases}

The case studies presented in this article are drawn from the Metropolitan Area of Styria (Austria), Ljubljana Urban Region (Slovenia) and rural Wales (UK), representing three out of eleven Living Labs within the Horizon 2020 ROBUST project (Rural-Urban Outlooks: Unlocking Synergies). Before introducing the case study regions, the various methods used within the project are described:

- $\quad$ Living Lab Approach [49-55],

- Community of Practice [56-58],

- Qualitative case study approach [59-66],

- Desk Research combining desk-based appraisal and documentary analysis,

- Semi-structured interviews and

- Analysis of quantitative data.

The project is focused on consolidated policy frameworks and governance models for mutually beneficial rural-urban synergies. The methodological approach of the Liv- 
ing Labs is region-specific, while over-arching Communities of Practice enable thematic comparison between different case studies and support the international exchange of experience and knowledge. Living Labs are place-based forms of experimental collaboration. Research takes place in a real-life setting, 'in which user-driven innovation is fully integrated within the co-creation process of new services, products, and societal infrastructures' [49]. They provide platforms in which different regional stakeholders, such as policymakers, researchers, businesses, service providers and citizens, contribute to the joint development of new approaches [50,51]. Through joint work, researchers and nonresearch actors benefit from shared knowledge [52]. As a consequence, Living Labs are not only a practical network of expertise and experience, but a new approach to foster community-driven innovation [53]. The advantages of this approach can be seen in the open system, that allows knowledge to flow both internally and externally. Products and services are more likely to be used by the target group if various stakeholders, as well as end users, are included in the development process. Furthermore, the research and innovation process is beneficially embedded in real and everyday living environments in order to integrate realistic challenges and effects. In recent years, the Living Lab approach has been increasingly applied in academic research projects, as scientists are encouraged to engage more with end users, such as governments, private businesses and other relevant stakeholders [54,55]. However, one challenge of the Living Lab approach is to motivate stakeholders to actively participate over a longer period of time [51,53].

A Community of Practice is a network of people with a common interest, practice or problem, who share knowledge and experiences [56,57]. Within ROBUST, this involves exploring multi-sectoral cooperation opportunities and identifying synergistic rural-urban governance structures [58]. Communities of Practice act as an analytical tool on a meta-level above the Living Labs by exploring thematic priorities in a broader, cross-regional context.

The selection of case studies is crucial in order to be able to draw conclusions for practitioners and politics [59]. In this article, case studies were selected based on shared results within a Community of Practice focussed on public infrastructures and social services. Seven out of eleven Living Labs chose this Communities of Practice, next to two others, as a priority in their research during the ROBUST project. Within the Community of Practice, initial identification and comparison of practice examples illustrated innovative concepts and revealed localised challenges. The thinning out of public transport and need for demand-oriented mobility solutions emerged as a common challenge. This encouraged the researchers to closely examine case studies in order to contribute potential solutions to this challenge. Three out of the seven participating Living Labs have previously developed mobility concepts. From these three, a total of five case studies addressing rural connectivity were chosen for in-depth analysis within this paper. The researchers primarily used a qualitative case study approach $[60,61]$. The method aims to investigate each specific case within a "real life" context [62], and to analyse the complexity of the various components within an example $[63,64]$. As a key step in the comparative qualitative analysis, we conduct a thorough data description. Qualitative, quantitative or mixed research methods are possible [65]. Research for the present article made use of a combination of desk-based appraisal and documentary analysis, alongside small-scale empirical research, including a small number of semi-structured interviews with key project stakeholders in the regions. Further, quantitative data were used in cases where project results needed to be verified, and such data were available. An intensive collaboration with project partners working closely with these case study examples simplified the access to data material. The lack of data in some cases, such as user satisfaction and ridership, only allowed parts of the examples to be analysed. Further, the diversity of the examples makes comparability difficult and thus represents a limitation of our analysis. Based on the available data and its description, criteria for comparison were developed: Governance arrangement, legal basis, connectivity to other systems, experienced obstacles and gains, as well as aspects of a sustainable development of the cases (see Tables S1 and S2). For each example, these criteria were elaborated, and in a further step, the results were brought together and discussed in a 
comparative way. Of special interest herein were the effects of services on the accessibility for different groups, the connectivity to public transport and usability as a 'first and last mile' feeder. Beyond the actual comparison, the intention was to share experiences and gain knowledge from other European regions. The case study approach supports mutual learning as the illustration of successful examples fosters beneficial insights [66]. Each case study region will now be briefly introduced.

The Metropolitan Area of Styria is one of seven regional administrative units in Styria and connects Graz, the second largest city in Austria, with 51 municipalities across the Graz-Umgebung and Voitsberg districts. With 498,186 inhabitants, the region is the most populated in Styria. Located in the south-eastern Alpine foreland, the region of about $2000 \mathrm{~km}^{2}$ is characterised by a relatively abrupt change from urban to rural, especially along the northern, eastern and western transition zone of the city to its hilly surroundings. Within the region, Graz is the major public transport hub. From there, the district of Graz-Umgebung has a very good train network to the north and south and the district of Voitsberg to the west, offering intra-regional commuter connections. In areas without a (sufficient) railway service, a large number of regional bus lines form the public transport network. Despite high frequencies on the main axes, bus services in the outlying areas are mainly designed for school transport, with few routes offered outside school hours. In Styria as a whole, private car ownership was 615.7 per 1000 inhabitants in 2019, meaning statistically there is more than one car for every two persons [67].

Ljubljana Urban Region lies in central Slovenia at the crossroads of two major European transport corridors. With $26 \%$ of the national population, Ljubljana Urban Region is the most populous and most urbanised region in Slovenia. The region also has the highest number of jobs, as the city of Ljubljana is the national capital, hosting administrative, educational and cultural services alongside considerable business activity. Every day, 77,000 people on average commute to Ljubljana from both within the region and further afield. Additionally, eight larger towns within the region serve as secondary employment centres, attracting further commuter traffic [68]. Nevertheless, most of the region's $26 \mathrm{mu}$ nicipalities, and a considerable part of the Municipality of Ljubljana itself, are rural. These rural areas have noticeably experienced in-migration, due to lower housing costs and proximity to employment, increasing rural-urban commuter traffic. However, declining public transport means most commuting is necessarily by private car. Additionally, declining local services, such as post offices, banking and shops, have increased the need for travel and reduced accessibility for those without a car. As of 2019, there were 560 cars per 1000 inhabitants in Slovenia [69,70].

Nine out of the twenty-two 'unitary authorities' in Wales are predominantly rural, with a combined population of approximately 1.02 million spread across $17,054.8$ square kilometres. Geographically, this includes much of the central land area, as urban populations are concentrated in the south (including capital city Cardiff) and, to a lesser extent, the North Wales coast. Rural Wales faces major challenges due to the remoteness of many areas, and limited infrastructure. Five medium-sized towns (pop. approx. 20,000) are the main service centres, linking with dispersed small market towns with populations between 750 and 5000 people. For access to major services, such as specialist hospital facilities, residents must travel to cities in Wales, or larger urban centres across the English border. However, the dispersed rural population presents challenges for connecting people with urban services. Transport connections are poor, with railways and arterial roads running east-west into England (a legacy of former extractive industries) rather than north-south within Wales. Although car ownership is high, a significant minority of residents depend on an increasingly limited public transport network to access employment and services [21]. There were 607.6 cars per 1000 inhabitants registered in Wales in 2018 [71].

In the following empirical section, we present the governance arrangements in terms of transport of all three regions. Further, we show two case studies from each of the Metropolitan Area of Styria and Ljubljana Urban Region, and one case collating two similar services offered in rural Welsh counties. 


\section{Analysis of Implemented Solutions for Rural-Urban Connectivity 5.1. Metropolitan Area of Styria}

In order to serve areas with insufficient public transport connections, alternative mobility concepts, such as on-demand mobility, recently developed within the Metropolitan Area of Styria. The introduction of future-oriented projects, such as micro-public transport or e-car sharing, is enabled by the Regional Management of the Metropolitan Area of Styria's long-standing establishment and regional, national and European networks, as well as governance arrangements and collaboration between political decision makers, public institutions and external experts. Resources for funding such projects can be provided at provincial, national and EU-level. A new legal basis in the province of Styria enables further funding opportunities. The Law on Planning and Development of the Province of Styria and its Regions (Landes- und Regionalentwicklungsgesetz 2018 (StLREG)) is a legal foundation for regional development budgets. This funding can be allocated to projects that are (i) based on intercommunal cooperation and (ii) part of the thematic focus according to the Regional Development Strategy 2020+ [72], which includes as one priority 'Enabling demand-oriented mobility \& intelligent transport solutions'. The allocation of funds is voted on an annual basis by the regional association. When introducing the regional development law, the Metropolitan Area of Styria has been committed to ensuring that projects of high regional importance can receive long-term support. These include the two Austrian examples, GUSTmobil and REGIOtim.

Beyond these implementation projects, the Regional Management cooperates with the city of Graz, the public transport-operator Holding Graz, the province of Styria and the Styrian Transport Alliance in order to develop a MaaS platform. With the objective to implement such a strategy in the entire region in the future, various modes of mobility are intended to be bundled and easily accessible in a central 'one-stop-shop'.

\subsubsection{REGIOtim}

REGIOtim is a network of multimodal mobility nodes located along public transport routes in the districts of Graz-Umgebung and Voitsberg, providing complementary services like e-car sharing, public charging stations, bicycle parking and micro-public transport [73]. The REGIOtim system aims to provide an affordable and stable alternative to car ownership that matches the local population's varying daily needs and serves them with $24 / 7$ accessibility.

The basis of the REGIOtim project is 'tim', an existing model of multimodal mobility in the City of Graz, developed by Holding Graz [74]. The name 'tim' abbreviates and combines the German words 'täglich.intelligent.mobil' (daily.intelligent.mobility). The tim concept was developed in 2015 within the project KombiMo II [74], funded by the Austrian Federal Ministry of Transport, Innovation and Technology. The roll-out of REGIOtim began in 2017 through a cooperation between the Regional Management, the City of Graz and Holding Graz. The first location in a peripheral municipality was implemented through the Interreg Central Europe project "Peripheral Access" [75]. Further REGIOtim nodes are funded by the European Regional Development Fund (EFRE/IWB) and the regional budget.

The Regional Management supports the coordination and implementation of REGIOtim together with the participating municipalities, and is responsible for networking activities between the stakeholders. To facilitate a continuous coordination process, the Regional Management, Holding Graz (as developer and tim brand owner) and externals jointly lead a Steering Committee, where they collaborate on important milestones, such as operational structures and innovations. The core topic is therefore the station-based e-car sharing [46]. Creating unified structures for all locations in- and outside of Graz helps to achieve an important objective of the project-the optimal and most flexible utilisation of regional synergies, which ultimately benefit the users.

The initial implementation phase of REGIOtim started in April 2018 and will last until March 2021. The first step in implementation was an analysis of potential locations for 
tim nodes. Evaluation of locations required the adaption of the location-based criteria from an urban context towards the needs of people in the suburban and rural areas. A location which is public, visible, scalable, easily accessible within walking and biking distance for many residents and connected to public transport is crucial for tim nodal sites [30]. Technical requirements, especially the grid capacity for e-carsharing and public charging, are crucial. In order to better assess the carsharing potential, initial analysis on combined location characteristics with research on local mobility needs is necessary. In many municipalities, railway stations are node locations, while other nodes may be located at municipal offices or existing park and ride facilities.

In November 2019, Hart bei Graz became the first municipality to implement a REGIOtim node. This new service including one Renault Zoe as station-based carsharing has made one local family refuse to buy another vehicle after theirs broke down, and another family actively selling theirs [76]. This so-called substitution effect was described as follows within a tim user survey in Graz: $65 \%$ of tim members in the city either replaced an existing private car or avoided the purchase of it [77]. A similar effect confirms a study on carsharing user groups in four German cities [31]. The first major evaluations and surveys of REGIOtim users will show the extent of this effect in suburban-rural areas. As of the end of September 2020, five tim nodes are in operation and 87 users have registered to use the e-carsharing system outside the city of Graz.

The Regional Management developed a set of performance criteria for operators and customer support, which serve as the basis for procuring external contractors. The contracted company is responsible for the $24 / 7$ customer service and provides the municipalities with support regarding accounting and system administration. The cooperation with Holding Graz guarantees attractive cost sharing terms for all tim locations in Graz and the region in terms of the IT system, specifically the server hosting and management. Furthermore, the booking platform structure implemented in Graz was adapted and expanded to cover all REGIOtim locations. Identifying the ideal fit for multi-layered framework conditions linking locally required services and regional carsharing partners posed a central challenge in developing and expanding tim's urban success into a peripheral-rural setting.

Furthermore, some aspects of the operation, that could be easily managed by Holding Graz as the city public transport and tim operator, proved significant obstacles for smaller municipalities with fewer resources and less experience. An example is the ability to register the necessary commercial law requirements for operating a carsharing system. In general, however, an interlinked multimodal mobility service has advantages over single solutions such as better public perception, visibility and scale of the service, and the number of e-carsharing vehicles available to individual users.

\subsubsection{GUSTmobil}

In the Metropolitan Area of Styria, city-suburban express trains provide transport connections between municipalities and the city of Graz, as well as to the long-distance railway network. In areas without adequate train services, regional buses complement the public transport network. However, the regional bus service is mainly focused on school transport. In order to serve remote areas with insufficient public transport connections, a demandresponsive mobility service was launched. GUSTmobil (Graz-Umgebung-Sammel-Taxi) is a micro-public transport service, which connects dispersed settlements to arterial public transport, and aims to ensure intra-local accessibility for everyday mobility [41].

The Regional Management of the Metropolitan Area of Styria coordinated stakeholder involvement in the planning and conceptualisation phase, and facilitated the following implementation process together with the operation company ISTmobil GmbH. After the Regional Management set-up an implementation budget for all 36 municipalities in the Graz-Umgebung district, 29 municipalities ultimately agreed to a three-year trial operation. The main reason cited by the municipalities that decided not to commit was the financial challenge, with additional micro-public transport investment costs adding to the already high payments for public transport. The 29 participating municipalities, with 105,000 
total inhabitants, collectively pay approximately $900,000 €$ per year including VAT towards GUSTmobil's operation [78].

GUSTmobil's acceptance among users is shown by the following usage data. From the start of the operations in July 2017 until the end of December 2019, 86,251 journey requests with 103,223 passengers have been provided. Collating individual call orders resulted in 58,286 shared trips, for an average occupancy rate of 1.77 per trip, with 375,651 total kilometres driven. Notably, the main user group is female and over 49 years old [78]. GUSTmobil's tariff structure is designed for short distances and first and last mile feeder trips. For at-home pick-ups for disabled people, the average journey is $5.3 \mathrm{~km} \mathrm{long;} 87 \%$ of these journeys do not lead to a main public transport hub, instead mainly providing access within the town for doctor's appointments or shopping [78].

GUSTmobil call orders are distributed unevenly across the service area. It can be deduced that the better and more comprehensive the existing public transport system in a municipality, the lower the number of micro-public transport orders. This reflects the prohibition on competition with public transport, required by the province of Styria as a funding body. Micro-public transport use also reflects the settlement structure of a municipality. The higher the degree of urban sprawl, the more likely it is that a journey will be completed without changing to public transport along the desired route. Importantly, the call order patterns in individual municipalities are influenced by application, communication and possible tariff support [32]. Thus, adapting the micro-public transport system to the existing public transport system remains one of the biggest challenges. This challenge is increased because micro-public transport users have little willingness to switch to public transport, especially on short trips to the nearest town centre for errands or shopping.

GUSTmobil's three-year trial phase officially ended in December 2020. The Regional Management of the Metropolitan Area of Styria has evaluated the project and, together with participating municipalities and external experts, proposed converting GUSTmobil into a permanent operation from 2021. One main objective for a further three years of operation is more integrated planning with existing public transport. In July 2020, the province of Styria launched new criteria for when to use micro-public-systems, public transport or a mix of both. According to these criteria, GUSTmobil rides are reasonable if people cannot reach a bus or train stop within $500 \mathrm{~m}$ walking distance. Call-taxi-rides can then be carried out for at least $7 \mathrm{~km}$ without the condition of changing to parallel public transport. These criteria allow more flexible use and simple communication on how and when a GUSTmobil journey is appropriate, which is crucial for the persistence of this complementary mobility service.

\subsection{Ljubljana Urban Region}

Local transport is administered by the municipalities and funded by the revenue generated from the fees, as well as the municipal and state subsidies. In Ljubljana Urban Region, the Ljubljana Public Transport Utility (Ljubljanski potniški promet) that is owned by the Municipality of Ljubljana is the main player, but there are several other transport companies (e.g., Arriva/Kam-bus) involved in local transport. The railway passenger transport is relatively weak and entirely managed by the state, but it is large enough to be considered when planning the transport development. The Local Transport Plans/Sustainable Mobility Plans are the key planning documents, and the small size of municipalities is the main obstacle for improved transport planning, especially between urban municipalities which can organise more financially viable urban and peri-urban transport, and more rural municipalities. However, EU funds (predominantly European Regional Development Fund (ERDF)) are used for the funding of activities and mobility infrastructure, while participation in various international projects, such as INTERREG, provided new ideas and opportunities to exchange experience and know-how. Newer forms of mobility, such as shared-hailed taxis, are mostly in a pilot phase and sources of funding for their long-term operation are being developed. 


\subsubsection{BicikeLJ}

In Ljubljana Urban Region, commuting and high car use have led to increased traffic congestion, affecting public transport functionality and increasing the pressure to widen the streets at the expense of cycle paths and pedestrian areas. To promote sustainable transport, the Municipality of Ljubljana has instead pursued multimodal solutions, including improvements to cycling infrastructure. The BicikeLJ bicycle-sharing system provides an opportunity to hire bicycles from self-service terminals located across the wider Ljubljana city centre and at park-and-ride facilities on the outskirts of the city. BicikeLJ particularly encourages shorter rides, as hire is free if the bicycle is returned to the nearest docking station within an hour. Use of the BicikeLJ system is hence practically free of charge, with a symbolic fee for pre-registration of $€ 3.00$ per year, or $€ 1.00$ for a week (catering to tourists and short-term visitors). BicikeLJ is the result of a public-private partnership between the City of Ljubljana and Europlakat, a subsidiary of the French advertising multinational JC Decaux [79]. In agreement with the City of Ljubljana, Europlakat manages the entire BicikeLJ system and assumes the costs of installation and maintenance. In return, the municipality has leased 360 advertising spaces in the city to Europlakat [79]. At launch in 2011, 300 BicikeLJ bicycles were available to users at 30 stations [80]. The popularity of the system has since exceeded all expectations and the network of stops and number of bicycles is still expanding. By 2017, there were 580 bicycles available to users at 58 stations. Between 2011 and 2018, 5,081,354 total bicycle borrowings were made.

Despite the enviable statistical indicators of the system's popularity, there are continuing challenges and scope for improved functionality. As mentioned in the literature review, a balanced spatial distribution of sharing stations and bicycles between the stations is crucial [47]. However, it poses a challenge in Ljubljana, like in many other urban regions. Most sharing stations are concentrated in the city centre and along main thoroughfares, which does not offer sufficient connectivity to the outskirts of the city. Connections beyond the city centre are primarily to park-and-ride facilities and shopping centres, and suburban stations are either rare or absent [81]. Despite the system's expansion, the distribution of sharing stations has changed little over time. Moreover, to keep the system operational, the distribution of bikes between stations must be ensured to offset unidirectional use in peak hours.

BicikeLJ was not developed to deal with the first and last mile gap, but rather to promote cycling in the city. It creates an incentive for multimodal mobility by complementing public transport and can further lead to less car usage within the city [46]. The objectives of the city management have been achieved through popularisation of the system, and high use of bicycles. Further development could explicitly tackle the first and last mile, shifting emphasis from (car-centred) park-and-ride facilities to integration with arterial transport routes. The key will be to manage the system and develop the potential for complementary connections.

\subsubsection{EURBAN Demand-Responsive Transport, Ljubljana Urban Region}

Within the Ljubljana Urban Region, rural service decline has increased the need for travel, yet inconvenient and costly public transport increases car dependency and poses accessibility problems for groups such as older people [16,18,21,22]. However, hilly terrain and dispersed settlement patterns make it difficult to provide public transport economically. Despite efforts to expand the city public transport network into surrounding rural municipalities along main commuter routes, frequency issues and first and last mile gaps remain.

In 2016, the Ljubljana Public Transport Utility introduced EURBAN, a fleet of electric vehicles for DRT [40]. Operated in partnership with the Municipality of Ljubljana, the main objective was, like in many other dispersed areas, to provide an alternative in times of low frequency or no public transport $[12,14,40]$. A test route was first established in the hilly, rural eastern part of the municipality, then extended to other rural routes. In 2019, participation in the Interreg Central Europe Peripheral Access project enabled the Regional 
Development Agency of Ljubljana Urban Region to develop a further pilot in the rural Municipality of Škofljica. The pilot aimed to close the first and last mile gap by providing EURBAN car connections between points otherwise not served by public transport [82]. Both EURBAN and the Škofljica pilot received initial coverage from national newspapers.

The EURBAN fleet consisted of 12 electric cars leased via public tender. Passengers were collected and dropped off at regular bus stops during low (or no) service timeslots, and the car could pick-up several passengers along the way. Booking was required at least two hours in advance. The ride cost the same as a single bus ride and was paid for in the same way - with an Urbana Transport Card or by phone. By integrating a new mobility service to the existing public transport payment option of the Ljubljana Urban Region, the basic idea of Mobility as a Service has already been considered within the implementation process [35]. The Škofljica pilot similarly provided a DRT service using two EURBAN vehicles and the public transport switchboard. The difference was that passengers were collected at 17 designated locations, otherwise not accessible without public transport, and dropped off at the nearest bus stop (and vice versa). The locations and bus connections were published on an online map and were marked on location with a noticeboard.

Ljubljana Public Transport Utility did plan a second phase of EURBAN offering rides to individual passengers outside published timeslots; due to low demand, the second phase was only partially implemented. EURBAN proved such a success along the initial route that a regular bus service was introduced. However, overall, EURBAN had few users: In 2018, an average of just five rides were made per month. The operational costs hence outweighed the accessibility benefits. The Škofljica pilot project had better, but still limited, results, transporting 158 passengers in 128 rides during the two-month trial [83]. The service proved most popular with high school students seeking off-peak transport, particularly in the afternoon. The Škofljica service was not renewed after the pilot ended in January 2020; EURBAN itself was phased out in early 2020.

Due to the low number of rides, EURBAN had little visibility in the communities where the service operated. However, the extent to which the service was actually known and understood among potential users has not been evaluated. A further question remains regarding service convenience. While both EURBAN and the Škofljica pilot provided connections to bus services, these were peri-urban routes with relatively low frequency. EURBAN's time slots were limited to off-peak hours only suited to some user groups, and were inconveniently short for multi-purpose trips. Additionally, the advance reservation system and time to arrive at the final destination likely did not match the instant convenience of a private car.

The Škofljica pilot was funded by the ERDF via Interreg, but the estimated cost for the municipality to continue to operate the scheme was 20,000€ per year for two vehicles. For a small municipality of 11,500 inhabitants, the cost was disproportionate to the benefits, and financial sustainability was the main reason for the decision not to continue with the scheme.

Demand-responsive micro-public transport in Ljubljana Urban Region still has potential as rural areas remain well populated, but depend on travel to urban service and employment centres [5]. Other municipalities have shown interest in reviving DRT projects to increase the scale of the system. However, the ultimately unsuccessful EURBAN case demonstrates the need for simplified booking, improved timing and extensive promotion, alongside fleet optimisation using routing, GPS and predictive algorithms to balance range limitations with user demand.

\subsection{Rural Wales}

While inter-regional transport, including rail and long-distance bus services, is sponsored and administered by the Welsh Government, local public transport is typically governed by the relevant local authority. Local authorities develop transport strategies, procure services, and issue contracts to commercial providers. The Transport (Wales) Act also enables the Welsh Government to give financial assistance to local authorities in order 
to facilitate transport, primarily through the Bus Services Support Grant. While most of this funding goes to public transport, some is ringfenced for community transport. Local authorities provide subsidies to transport services as a public good; this is particularly important in rural areas where many routes are otherwise not financially viable. In some cases, local authorities directly provide transport services themselves.

\section{Bwcabus and Grass Routes, Rural Wales}

Over the past decade, austerity budgets and falling patronage have seen considerable decline in rural bus services. Between 2010 and 2016, funding for buses in Wales fell by $20 \%$ [84]. Cuts disproportionately affect rural areas, where a combination of population dispersal and topology makes provision costly, and under-developed rail infrastructure affords few alternative options. Many rural residents necessarily depend on private cars [16], reflected in higher levels of car ownership in rural compared to urban Wales $[85,86]$. However, rural Wales has an ageing demographic and older residents are less likely to have access to a car [21]. Loneliness and social isolation are also of considerable concern in Wales [87].

The large geographical scale of rural areas in Wales creates logistical and financial challenges for operating a regularly timetabled bus network [39] capable of linking outlying places to service centres. The demand-responsive transport services Bwcabus and Grass Routes were implemented to address this challenge by enabling journeys that could not otherwise be made by car. The services dynamically plan each day's routes and stops according to individual users' needs, using mapping, routing and GPS technologies. Bwcabus and Grass Routes users call a bookings line in advance and are collected at their nearest bus stop. By only running where and when needed, the services are intended to reduce costs and emissions, while facilitating service access and social meeting.

Bwcabus and Grass Routes are adaptations enabling public transport connectivity in rural areas where fixed timetables are no longer viable. These services can also complement existing public transport by providing a first and last mile solution, and connecting users to bus and rail interchanges for onwards journeys. An evaluation has shown that Bwcabus has cut average journey times to the nearest employment centre from 52 to 27 min [86]. The accessibility of the region was therefore massively improved [16-18].

Bwcabus, operated in partnership between local authorities and the Welsh Government, covers three predominantly rural counties: Carmarthenshire (pop. 187,568), Ceredigion (pop. 72,992) and Pembrokeshire (pop. 125,055). Fares are charged by distance, but external funding remains necessary to sustain and expand services. Bwcabus has received funding from the ERDF, European Agricultural Fund for Rural Development (EAFRD), Welsh Government, local authorities and the University of South Wales as a sponsoring partner. Grass Routes is operated by Monmouthshire County Council (pop. 92,142), with grant support from the Welsh Government. The service is subsidised, enabling a flat-rate fare system. Grass Routes costs approximately $£ 530,000$ per year to operate, and provides 58,000 annual passenger journeys [85]. The Grass Routes fleet is also used for school transport, reducing costs through shared resources.

Bwcabus and Grass Routes are well-established. Bwcabus was first introduced in 2009, and has expanded geographical coverage over time. Grass Routes was implemented in 2004. The service has also grown over time, with Welsh Government funding used to expand the in-house fleet. In some areas, Grass Routes has now taken over routes that were formerly run on a regular timetable.

The major limitations for Bwcabus and Grass Routes are service availability, accessibility and technology. Service availability is limited in terms of fleet capacity and hours of operation. As user pre-registration and advance booking are required, ad hoc journeys cannot be accommodated, and the services are less likely to be used by tourists and younger people. Grass Routes also only operates between 9 am and 4.30 pm, hence is unavailable for typical commuter trips. Further, the in-house fleet used to operate Grass Routes is also used for school transport. While this restricts the Grass Routes services that can be 
provided during school transport peak times, it also makes 'double' use of the resource. Although some journeys on Grass Routes may potentially be booked to railway stations or bus interchanges for onwards journeys, precise data on this are not available. Bwcabus, by contrast, is intended to be able to offer connections to bus interchanges for longerdistance TrawsCymru services. Consequently, the general conditions for multimodality are given [34].

Accessibility poses challenges as users need to be able to physically book a journey and meet the bus (although passengers with disabilities can be collected from home, where possible). However, perceived accessibility can be more problematic: Without fixed routes and obvious infrastructure, DRT services can be invisible to many residents, who may also believe that DRT is only for certain kinds of users [86]. A recent evaluation found that many Monmouthshire residents were either not aware of Grass Routes, or did not believe the buses were available to their destinations [85]. This fact emphasises the importance of an active demand management plan including information and marketing activities $[28,32,33]$.

In Wales, technology for rural DRT has not yet been digitalised. Digital solutions could make the services more responsive from a user perspective, although current rural DRT users are typically from demographics less likely to use digital technology. Bwcabus and Grass Routes use phone lines for booking, and there is evidence from other projects that using call centres for DRT can increase overall operating costs [86]. Future fleet upgrades to ultra-low-emissions vehicles (ULEVs) will also require significant investment.

The challenges for rural DRT in Wales can be viewed as opportunities for future development. This is certainly the case for multimodal complementary mobility. DRT has the capacity to improve integration with regional and national transport networks, but this requires complex coordination between stakeholders, ICT and financing. Timetabling, for example, can mean that DRT passengers have long waits before their onward bus or train journeys. These are difficult logistical challenges to solve, but they equally point towards future solutions that may move DRT closer to Mobility as a Service [48].

\section{Discussion}

The Metropolitan Area of Styria, Ljubljana Urban Region and rural counties in Wales, like many other European regions, increasingly need to offer sustainable alternatives to the conventional transport infrastructure and cost-effective solutions to complement public transport systems. The case studies presented above show a diversity of smallscale multimodal initiatives that overcome missing links in public transport networks by accompanying other forms of mobility. As these examples illustrate, demand-responsive modes and alternative forms of mobility can complement existing public transport and enable accessibility in rural areas [16-18]. As mobility solutions for the first and last mile, these initiatives can further help improve rural-urban connectivity. In this section, we discuss comparative findings between the case studies, based on the defined criteria. Therefore, we will look at the governance arrangements and legal basis of the systems, and identify challenges and limitations, as well as opportunities for long-term sustainability; we turn to the future potential for development and policy recommendations in the conclusion to follow.

The five case studies presented result from research within the Horizon 2020 ROBUST project's Community of Practice on public infrastructure and social services. Three rural examples, Bwcabus/Grass Routes, GUSTmobil and EURBAN, are shared DemandResponsive Transport services, utilising existing public transport stops as pick-up and drop-off locations [37]. BicikeLJ is an urban bike-sharing system with fixed stations [46], available within Ljubljana's pedestrianised city centre, that has been expanding to parkand-ride facilities and peripheral shopping areas. REGIOtim is a regional network of multimodal mobility nodes, connecting micro-public mobility offers to public transport in order to promote multimodality [34]. This selection is, of course, not a complete picture of all potential complementary mobility solutions, but draws attention to the need for approaches resulting from and responsive to specific local needs. Further examples of mul- 
timodal complementary mobility not considered here could include demand-responsive and / or micro-public transport with door-to-door or stop-to-door collection, and shared mobility through commercial or voluntary carsharing [37]. Table 1 summarises the variety of modes, interventions and designs shown by the case studies.

Table 1. Overview of the variety of modes, interventions and designs shown by the case studies.

\begin{tabular}{|c|c|c|c|c|}
\hline Case Study & Concept & Modes & How Complementary? & Design \\
\hline $\begin{array}{l}1 \text { REGIOtim } \\
\text { Styria, Austria }\end{array}$ & \begin{tabular}{ll}
\multicolumn{2}{l}{ Connection of } \\
$\cdot \quad$ & Public \\
$\cdot$ & Micro-Public \\
$\cdot$ & Shared \\
$\cdot$ & Individual
\end{tabular} & $\begin{array}{l}\text { e-carsharing } \\
\text { Charging } \\
\text { Cycling } \\
\text { (Micro-) Public } \\
\text { transport }\end{array}$ & $\begin{array}{l}\text { Enabling users to combine } \\
\text { multiple modes of transport, with } \\
\text { the existing public transport } \\
\text { system as a base. }\end{array}$ & $\begin{array}{l}\text { Fixed-Schedule } \\
\text { Demand-Responsive } \\
\text { Flexible }\end{array}$ \\
\hline $\begin{array}{l}2 \text { GUSTmobil } \\
\text { Styria, Austria }\end{array}$ & $\begin{array}{l}\text { Micro-Public } \\
\text { Transport }\end{array}$ & Shared-hailed taxi & $\begin{array}{l}\text { Enables reaching public transport } \\
\text { or a city centre from dispersed } \\
\text { areas without a private car. }\end{array}$ & Demand-Responsive \\
\hline $\begin{array}{l}3 \text { BicikeLJ } \\
\text { Ljubljana, Slovenia }\end{array}$ & Shared Mobility & Cycling & $\begin{array}{l}\text { Supporting car-free urban } \\
\text { transport and connecting users to } \\
\text { key transport routes and public } \\
\text { transport hubs. }\end{array}$ & Flexible \\
\hline $\begin{array}{l}4 \text { EURBAN } \\
\text { Ljubljana, Slovenia }\end{array}$ & $\begin{array}{l}\text { Micro-Public } \\
\text { Transport }\end{array}$ & Shared-hailed taxi & $\begin{array}{l}\text { Substitutes public transport at } \\
\text { off-peak hours in rural areas with } \\
\text { scarce public transport, but also } \\
\text { enables reaching the public } \\
\text { transport network from distant } \\
\text { rural areas without use of a } \\
\text { private car. }\end{array}$ & Demand-Responsive \\
\hline $\begin{array}{l}5 \text { Bwcabus and } \\
\text { Grass Routes } \\
\text { Rural Wales }\end{array}$ & $\begin{array}{l}\text { Micro-Public } \\
\text { Transport }\end{array}$ & Call-a-bus & $\begin{array}{l}\text { Sustaining rural transport services } \\
\text { by replacing timetables with } \\
\text { demand-responsive routing. }\end{array}$ & Demand-Responsive \\
\hline
\end{tabular}

Note: More detailed information on the elaborated criteria can be found in Tables S1 and S2 in the Supplementary Material. Source: Own compilation, 2021.

The main intention of implementing BicikeLJ and REGIOtim was to drive a shift from motorised private transport towards multimodality and sustainable transport. These examples succeeded in implementing a flexible and attractive alternative to the private car. Their design and user-friendliness present pull measures, which encourage behaviour change, as argued in the literature [1,4,27]. EURBAN, GUSTmobil, Bwcabus and Grass Routes, however, were primarily introduced to improve accessibility and to avoid social exclusion. DRT serves especially the social aspect of mobility, as it offers increased mobility options for those population groups without a private car [1,24].

User-friendliness poses challenges for accessibility, however. For example, booking a DRT journey by telephone takes more effort than using an app and may be particularly perceived as a hurdle by younger demographics, yet sufficient broadband coverage for mobile booking systems is not always available in rural areas. Bwcabus and Grass Routes both require pre-registration and advance booking, and EURBAN similarly required a minimum of two hours' notice, which implies planning ahead. Pre-registration poses an entry barrier for one-time users such as tourists, and may be perceived as too time consuming for infrequent local users. This is reflected in the numbers of users. GrassRoutes has long been established, but like EURBAN, it is mostly used by people who depend on it. Therefore, as broadly discussed in the literature [41-43], the application of intelligent software systems is indispensable to increase user satisfaction and the number of riders. The better and more flexible the service, the more attractive it becomes to different user groups. In turn, service availability increases. GUSTmobil can be highlighted as an example. The service offers both telephone and mobile app booking with short waiting times, opening 
the service to a broader audience. As this suggests, how the booking process is designed offers considerable potential to broaden the user base and increase occupancy.

As a convenient form of shared mobility, BicikeLJ reaches a large audience. At the same time, the service is limited by only being offered in the city centre and a few suburban locations. This current limitation, however, also holds the prospect of enlarging the network in the future. Expanding further into the outskirts of the city and beyond would provide coverage for first and last mile gaps in the existing public transport system. REGIOtim offers lessons here, having successfully transformed the concept of an urban multimodal node into a solution adapted to the wider peri-urban environment. Both examples further serve as a reminder of the value of small-scale multimodal solutions that complement, rather than compete, with rural-urban public transport arteries. Shaheen et al. [45] further argues that sharing assets, such as bikes and cars, enables an efficient use of resources and also reduces costs for individuals by saving fuel and repair costs.

The complementary role of such services necessitates careful coordination with existing public transport systems. From a user perspective, effective coordination should result in reduced waiting times for onward connections, and routing services from a single source. From a management perspective, the success of complementary projects strongly depends on local and regional governance arrangements from an administrative and financial point of view, as well as the legal framework. Connecting different services means connecting different operators, stakeholders and interests. These new alliances require a high degree of willingness to open-up systems, create interfaces and work in cooperation on the bigger picture instead of sticking to isolated implementations.

In all five examples, the common element is substantial involvement and planning by local and regional authorities, to decide initial steps and implement an operational framework. While the operators are diverse (a local authority in the case of Grass Routes, a public utility for EURBAN, and a combination of municipal services and private contractors for REGIOtim and GUSTmobil), all operate via a subsidised framework provided by public authorities. In addition, multi-level governance arrangements and the willingness for co-operation with all stakeholders have proven to be fundamental.

EURBAN is an example of a project that grew organically from the municipal to regional level, assisted by the activities of an Interreg project. However, the implementation of a further pilot in the rural Municipality of Škofljica showed that multi-party governance arrangements are much more complex and require more time and commitment by the partners involved. In particular, the difference in the budgets and priorities (both of the inhabitants and the municipal councils) between a large, highly urban municipality like Ljubljana, which is also a capital city, and the much smaller, more rural municipalities surrounding, hampered the expansion and continuation of the project [2]. Bwcabus is an interesting example because it operates within three separate local authorities and also integrates with the national TrawsCymru network. Governance is hence a complex partnership arrangement between various stakeholders: Local authorities, the Welsh Government, contracted bus operators, Traveline (booking and travel advice line) and the University of South Wales (which originally developed the project). GUSTmobil and REGIOtim have been promoted by the Regional Management of the Metropolitan Area of Styria. Due to the spatial conditions of rural, peri-urban and urban areas and different socioeconomic and demographic developments, the challenge lies in coordinating the various needs and interests across the region, as well as in the collaborative and mutual benefit. As a service-oriented intermediary institution, the Regional Management acts as an interface between the various stakeholders within the region and thus has the role to advise, moderate and drive regional development processes. This shows that the governance structures differ from region to region and that the implementation process as well as the success of projects are highly dependent on local requirements.

Governance arrangements can also be used to promote the integration of isolated projects into a holistic approach towards MaaS [48]. It brings together single pieces of a puzzle to form a comprehensive mobility picture. To date, MaaS has been primarily ori- 
ented towards cities. Yet, it has clear potential wherever complementary mobility services, such as those we have profiled here, exist alongside backbone public transport systems. The Metropolitan Area of Styria is planning to be a MaaS pilot region in Austria, with the public sector coordinating the implementation process alongside broad participation from various stakeholders. REGIOtim and GUSTmobil are both services that are conceptualised as part of the existing public transport network and set-up on the regional project level. Grass Routes is largely used to make short journeys for shopping and appointments, for example, and does not directly connect to other forms of public transport. However, a report commissioned for Monmouthshire County Council [85] does look ahead to a model much more akin to MaaS. There is clear potential for future development here.

The governance of the BicikeLJ cycle scheme involves stakeholders with vastly different motives. While the Municipality of Ljubljana is focused on sustainable mobility, the advertising company that helps to run the scheme is driven by profits and visibility. Initially, there was concern over conflicts with Public Transport Utility in fear that the cycle scheme will result in lower bus passenger numbers and thus lower revenue of the public utility, but it immediately emerged that this was not the case. Nowadays, the Municipality, the Public Transport Utility and the scheme operator monitor and plan together further expansion of the scheme, thus reinforcing sustainable mobility and the benefits of all the parties involved. Comparison of the DRT examples presented in this article further shows that scale and visibility are important factors. For example, EURBAN was too limited to relatively small areas and ran for too short a time to be broadly recognised by the local population. Conversely, GUSTmobil, REGIOtim, Bwcabus and Grass Routes cover larger areas, likely increasing their visibility and recognition over time and helping to increase the user base. The BicikeLJ cycle scheme was designed as a municipal initiative, but was successfully outsourced in combination with advertising space, thus maintaining the operator's motivation to expand the network. In addition, multi-level financial supportfrom local and regional authorities, to the state and the European Commission, as well as public-private partnerships and corporate donations-is crucial to enable both the initial development of services and their operation on an affordable tariff system.

Relatedly, many projects depend on private companies for maintenance and operational support, due to the lack of human resources and expertise in small rural municipalities. These dependencies raise the question of what will happen to the services once project funding runs out. REGIOtim and GUSTmobil's continuation is secured through a regional budget that releases funds for intercommunal projects. The latter is also financially supported by the regional transport department of the province of Styria, which is designed for long-term funding. BicikeLJ's funding is secured by a public-private partnership, and Bwcabus, now in operation for over a decade, has been able to integrate multiple targeted but short-term funding streams alongside continued regional, national and EU-funding, primarily through the ERDF. Obviously, Brexit means that this funding will no longer be available after the current funding period. While a replacement 'Shared Prosperity Fund' has been proposed by the UK Government, there has to date been little concrete information about what this would entail. Financial uncertainty, however, does create challenges for service continuity, as shown by the EURBAN example. Just as cuts to public transport contribute to rural marginalisation [11], lost complementary services have knock-on effects for users who may come to depend on them for access to everyday activities.

\section{Conclusions}

This article has engaged with the practical challenge of facilitating a modal shift from the private car towards more sustainable forms of passenger transport within the wider context of rural-urban connectivity. In this concluding section, we return to our initial research questions, and look ahead to future directions for multimodal complementary mobility. In Europe, the existing transport system remains highly oriented towards 'automobility', creating negative effects for the environment, health and within the built environment. However, while much of the focus on innovation in sustainable transport has 
occurred within urban contexts, many rural areas struggle with the logistics of providing public transport in dispersed or remote settlements with low population density and, often, under-developed infrastructures $[16,85,86]$. As rural and urban areas are not separate spheres but mutually interconnected, these differences have implications for effective rural-urban linkages and future sustainable development. Public transport systems are crucial arteries for rural-urban connectivity, yet can rarely provide blanket coverage and flexible access. We have advanced the concept of multimodal complementary mobility services as a means of framing small-scale, localised implementations that are both flexible and demand-responsive, and, by facilitating public transport journeys, can contribute to sustainable, accessible rural-urban connectivity.

In the first of our two research questions, we asked: What are the promoting and inhibiting factors for multimodal complementary transport systems? As we have shown, there is no one-size-fits-all model for multimodal complementary mobility. Rather, approaches that are place-based and tailored can improve accessibility, especially where existing public transport is limited or infrastructures unviable. Small-scale solutions can in turn contribute to longer-range rural-urban connectivity by improving convenience for the user and filling first and last mile gaps in existing provision. Several promoting factors are important here, including: Well-established governance arrangements; close coordination between stakeholders; ICT; marketing and promotion of services; the support and expertise of regional bodies; an effective interface with existing public transport to support multimodal mobility and the concept of Mobility-as-a-Service. The absence of, or poor performance in, many of these aspects will inhibit development and user take-up. Additional inhibiting factors include user-friendliness, geographical reach and the long-term viability of project funding and financial models.

That is why we asked in our second research question: How can the operation of multimodal complementary systems be sustained over a longer-term perspective? Looking at the inhibiting and promoting factors of the presented examples, three main aspects can be named for a durable implementation. Especially, the unsuccessful example of EURBAN allows for instructive conclusions.

The first lesson that can be drawn of the examples is the necessity of improving the operability of systems in order to increase user-friendliness and utilisation rate. These aspects can be achieved by densifying the network of multimodal mobility opportunities; increasing visibility of transport options to the local population by marketing strategies and information campaigns; and creating incentives, such as bundled price ticket packages and reduced prices for regular users [30,32,33]. Further, ongoing innovations in software systems can increase efficiency and provide real-time travel information, efficient routing, ride pooling and automated journey reminders, and integrate multimodal complementary systems in the existing public transport network [41-43]. This leads to the second finding: Small-scale mobility services need to be combined with other mobility modes and routes and thus integrated in a broader transport system. Isolated projects rapidly become expensive and are only matched to a small user group. Within interlinked mobility systems, not only the small, comprehensive services receive advantages. Our case studies show that multimodal nodes can help to put public transport in a more attractive spotlight and, coupled with these complementary services such as sharing offers, make it possible to reduce private car journeys while maintaining flexibility. A similar approach is confirmed by Smith et al. [48]. This points to future directions in Mobility as a Service (MaaS) [35]. The complementary systems discussed in this article could serve as pieces that, in innovative combination and interaction with other services, can enable a new level of flexible multimodality. MaaS can push the transition from isolated project-based concepts to an integrated sustainable approach. Thirdly, well-established governance arrangements play an essential role in implementing and sustaining multimodal complementary systems. Legal foundations and well-functioning cooperation can support long-term financing. We have also learned from the case studies that financing such services in the long term is hardly possible without corresponding subsidies and the commitment of public bodies. 
However, like public transport, multimodal complementary services must be seen as an important investment to improve social and environmental outcomes. It is necessary to plan mobility as a whole and in an interlinked way to facilitate the long-term endurance of all systems. In this respect, there is often a need to raise awareness that, for example, micro-public transport can also be a perfect feeder to a carsharing vehicle, or that a bus stop complemented by a safe bicycle infrastructure can increase the quality of both modes. The most important factors and arguments for the mobility sector are to offer a sustainable quality of supply and to promote functionality and connectivity in rural areas. The modern technologies enable a wide range of possibilities within the mobility sector. Nevertheless, the introduction of flexible and sustainable mobility concepts needs, above all, a representation of interests, openness on the part of the responsible stakeholders and supporting structures that coordinate the development and implementation process. The results reinforce these necessities, which is why the authors argue for new cooperation models and supporting structures in the mobility sector in the rural-urban interface.

Supplementary Materials: The following are available online at https:/ / www.mdpi.com/2071-105 0/13/3/1280/s1, Table S1: Overview of the governance arrangements and legal basis of the presented mobility concepts and Table S2: Overview of the obstacles, gains and outlooks of the presented mobility concepts.

Author Contributions: Conceptualization, L.B., A.R., B.G.-H., J.K., M.H. and T.O.-W.; methodology, L.B., A.R., B.G.-H., J.K., M.H. and T.O.-W.; investigation, A.R., B.G.-H., J.K. and M.H.; writingoriginal draft preparation, L.B., A.R., B.G.-H., J.K. and M.H.; writing-review and editing, L.B., A.R., B.G.-H., M.H. and T.O.-W.; visualization, L.B. All authors have read and agreed to the published version of the manuscript.

Funding: This research was funded by the European Union's Horizon 2020 research and innovation programme under grant agreement No. 727988. The content of this publication does not reflect the official opinion of the European Union. Responsibility for the information and views expressed therein lies entirely with the authors.

Conflicts of Interest: The authors declare no conflict of interest.

\section{References}

1. Batty, P.; Palacin, R.; González-Gil, A. Challenges and opportunities in developing urban modal shift. Travel Behav. Soc. 2015, 2, 109-123. [CrossRef]

2. Mattioli, G. Transport needs in a climate-constrained world. A novel framework to reconcile social and environmental sustainability in transport. Energy Res. Soc. Sci. 2016, 18, 118-128. [CrossRef]

3. European Environmental Agency. Passenger and Freight Transport Demand in Europe. European Environmental Agency: Brussels, Belgium. 2019. Available online: https://www.eea.europa.eu/data-and-maps/indicators/passenger-and-freighttransport-demand/assessment-1 (accessed on 30 September 2020).

4. Banister, D. Cities, mobility and climate change. J. Transp. Geogr. 2011, 19, 1538-1546. [CrossRef]

5. Schiller, P.L.; Kenworthy, J. An Introduction to Sustainable Transportation: Policy, Planning and Implementation, 2nd ed.; Routledge: London, UK, 2017.

6. Nieuwenhuijsen, M.J.; Khreis, H. Car free cities: Pathway to healthy urban living. Environ. Int. 2016, 94, 251-262. [CrossRef] [PubMed]

7. Urry, J. The 'system' of automobility. Theory Cult. Soc. 2004, 21, 25-39. [CrossRef]

8. European Commission. The European Green Deal; Communication from the Commission to the European Parliament, the European Council, the Council, the European Economic and Social Committee and the Committee of the Regions; European Commission: Brussels, Belgium, 2019.

9. Freudendal-Pedersen, M.; Kesselring, S.; Servou, E. What is Smart for the Future City? Mobilities and Automation. Sustainability 2019, 11, 221. [CrossRef]

10. European Commission. Cities of Tomorrow: Challenges, Visions, Ways Forward; Directorate General for Regional Policy; European Commission: Brussels, Belgium, 2011.

11. Bock, B.B. Rural Marginalisation and the Role of Social Innovation. A Turn towards Nexogenous Development and Rural Reconnection. Sociol. Rural. 2016, 56, 552-573. [CrossRef]

12. Halseth, G.; Markey, S.; Ryser, L. Introduction. In Service Provision and Rural Sustainability: Infrastructure and Innovation; Halseth, G., Markey, S., Ryser, L., Eds.; Routledge: London, UK, 2018; pp. 3-18. 
13. Farrington, J.; Farrington, C. Rural accessibility, social inclusion and social justice: Towards conceptualisation. J. Transp. Geogr. 2005, 13, 1-12. [CrossRef]

14. Skerratt, S. Hot Spots and Not Spots: Addressing Infrastructure and Service Provision through Combined Approaches in Rural Scotland. Sustainability 2010, 2, 1719-1741. [CrossRef]

15. Hamilton, C. Changing Service Provision in Rural Areas and the Possible Impact on Older People: A Case Example of Compulsory Post Office Closures and Outreach Services in England. Soc. Policy Soc. 2016, 15, 387-401. [CrossRef]

16. Shergold, I.; Parkhurst, G.; Musselwhite, C. Rural car dependence: An emerging barrier to community activity for older people. Transp. Plan. Technol. 2012, 35, 69-85. [CrossRef]

17. Velaga, N.R.; Beecroft, M.; Nelson, J.D.; Corsar, D.; Edwards, P. Transport poverty meets the digital divide: Accessibility and connectivity in rural communities. J. Transp. Geogr. 2012, 21, 102-112. [CrossRef]

18. Vitale Brovarone, E.; Cotella, G. Improving Rural Accessibility: A Multilayer Approach. Sustainability 2020, 12, 2876. [CrossRef]

19. Chandra, S.; Bari, M.E.; Devarasetty, P.C.; Vadali, S. Accessibility evaluations of feeder transit services. Transp. Res. Part A Policy Pract. 2013, 52, 47-63. [CrossRef]

20. Vreeker, R.; Nijkamp, P. Multicriteria Evaluation of Transport Policies. In Handbook of Transport Strategy, Policy and Institutions; Button, K.J., Hensher, D.A., Eds.; Elsevier: Oxford, UK, 2005; pp. 507-526.

21. Powell, J.; Keech, D.; Reed, M. What Works in Tackling Rural Poverty: An Evidence Review of Interventions to Improve Transport in Rural Areas; Wales Centre for Public Policy: Cardiff, UK, 2018.

22. Smith, N.; Hirsch, D.; Davis, A. Accessibility and capability: The minimum transport needs and costs of rural households. J. Transp. Geogr. 2012, 21, 93-101. [CrossRef]

23. Levitas, R.; Pantazis, C.; Fahmy, E.; Gordon, D.; Lloyd, E.; Patsios, D. The Multidimensional Analysis of Social Exclusion; Department for Communities and Local Government and Social Exclusion; University of Bristol: Bristol, UK, 2007.

24. Lucas, K. Transport and social exclusion: Where are we now? Transp. Policy 2012, 20, 105-113. [CrossRef]

25. Banister, D. Cities, Mobility, and Climate Change. J. Ind. Ecol. 2008, 11, 7-10. [CrossRef]

26. Keeling, D.J. Transportation geography: Local challenges, global contexts. Prog. Hum. Geogr. 2009, 33, 516-526. [CrossRef]

27. Randall, L.; Berlina, A.; Grunfelder, J.; Kempers, A.; Eggers, A. The Influence of Sociocultural Factors on the Uptake of Innovative Rural Mobility Solutions. $\mathrm{WP}_{2}$, GoA6; MAMBA. 2020. Available online: https://www.mambaproject.eu/wp-content/uploads/2020/0 6/FINAL_MAMBA_2.6-Sociocultural-study.pdf (accessed on 11 January 2021).

28. Lättman, K.; Friman, M.; Olsson, L.E. Perceived Accessibility of Public Transport as a Potential Indicator of Social Inclusion. Soc. Incl. 2016, 4, 36-45. [CrossRef]

29. Preston, J.; Rajé, F. Accessibility, mobility and transport-related social exclusion. J. Transp. Geogr. 2007, 15, 151-160. [CrossRef]

30. Tamme, O. Ländliche Mobilität in Österreich. Eine Bestandsaufnahme; Facts \& Features der Bundesanstalt für Bergbauernfragen; Medieninhaber (Verleger) und Herausgeber; Bundesanstalt für Bergbauernfragen: Vienna, Austria, 2015.

31. Nehrke, G.; Loose, W. Nutzer und Mobilitäts-Verhalten in Verschiedenen CarSharing-Varianten; Bundesverband CarSharing: Berlin, Germany, 2018.

32. Government Office for Science. A Time of Unprecedented Change in the Transport System; The Future of Mobility; Foresight: London, UK, 2019.

33. Brake, J.; Mulley, C.; Nelson, J.D.; Wright, S. Key lessons learned from recent experience with Flexible Transport Services. Transp. Policy 2007, 14, 458-466. [CrossRef]

34. Deutsches Institut für Urbanistik. Was ist eigentlich intermodaler und multimodaler Verkehr? Berichte 2018, 1, 18.

35. Ambrosino, G.; Nelson, J.D.; Boero, M.; Pettinelli, I. Enabling intermodal urban transport through complementary services: Flexible Mobility Services to the Shared Use Mobility Agency. Res. Transp. Econ. 2016, 59, 179-184. [CrossRef]

36. STS and Verkehrplus. Mikro-ÖV Strategie Steiermark; Studie im Auftrag des Landes Steiermark; Amt der Steiermärkischen Landesregierung: Graz, Austria, 2016.

37. Institution of Mechanical Engineers; Community Transport Association. The Future of Demand Responsive Transport. Available online: https:/ / ctauk.org/wp-content/uploads/2018/05/The-Future-of-Demand-Responsive-Transport-1.pdf (accessed on 18 September 2020).

38. Amt der Niederösterreichischen Landesregierung. Mikro ÖV: Wieviel Flexibilität ist Erlaubt? Amt der Niederösterreichischen Landesregierung: St. Pölten, Austria, 2017.

39. Li, X.; Quadrifoglio, L. Feeder transit services: Choosing between fixed and demand responsive policy. Transp. Res. Part C 2010, 18, 770-780. [CrossRef]

40. Edwards, D.; Watkins, K.E. Comparing Fixed-Route and Demand-Responsive Feeder Transit Systems in Real-World Settings. Transp. Res. Rec. 2013, 2352, 128-135. [CrossRef]

41. Mulley, C.; Nelson, J.D. Flexible transport services: A new market opportunity for public transport. Res. Transp. Econ. 2009, 25, 39-45. [CrossRef]

42. Inturri, G.; Le Pira, M.; Giuffrida, N.; Ignaccolo, M.; Pluchino, A.; Rapisarda, A.; D'Angelo, R. Multi-agent simulation for planning and designing new shared mobility services. Res. Transp. Econ. 2019, 73, 34-44. [CrossRef]

43. Franco, P.; Johnston, R.; McCormick, E. Demand responsive transport: Generation of activity patterns from mobile phone network data to support the operation of new mobility services. Transp. Res. Part A Policy Pract. 2020, 131, 244-266. [CrossRef] 
44. Canzler, W. Die Soziale Aufgabe Von Verkehrsinfrastrukturpolitik. In Handbuch Verkehrspolitik; Canzler, W., Knie, A., Schwedes, O., Eds.; Springer VS: Wiesbaden, Germany, 2014; pp. 1-22.

45. Shaheen, S.; Chan, N. Mobility and the Sharing Economy: Potential to Facilitate the First- and Last-Mile Public Transit Connections. Built Environ. 2016, 42, 573-588. [CrossRef]

46. AustriaTech—Gesellschaft des Bundes für technologiepolitische Maßnahmen GmbH. Sharing Mobility—Gemeinsam Mobil; Österreichs Sharing Community und die Potenziale für Städte und Gemeinden; AustriaTech: Vienna, Austria, 2019.

47. Büttner, J.; Mlasowsky, H.; Birkholz, T.; Gröper, D.; Emberger, A.C.F.G.; Petersen, T.; Robert, M.; Reth, S.S.V.P.; Blumel, H.; Rodriguez, C.R.; et al. Optimising Bike Sharing in European Cities. A Handbook; OBIS, s.l. 2011. Available online: https: / / ec.europa.eu/energy/intelligent/projects/sites/iee-projects/files/projects/documents/obis_handbook_en.pdf (accessed on 27 November 2020).

48. Smith, G.; Hensher, D.A. Towards a framework for Mobility-as-a-Service policies. Transp. Policy 2020, 89, 54-65. [CrossRef]

49. European Commission. Living Labs for User Driven Open Innovation; European Commission: Brussels, Belgium, 2009. Available online: https://www.eurosportello.eu/sites/default/files/Living\%20Lab\%20brochure_jan09_en_0.pdf (accessed on 27 November 2020).

50. Kobzeva, M.; Knickel, K. Interactions and Dependencies Between Rural, Peri-Urban and Urban Areas and Contemporary Governance Approaches; Synthesis Report Rapid Appraisals_Deliverable 2.4.: Bad Soden am Taunus, Germany, 2018.

51. Hess, A.; Magin, D.; Koch, M.; Tamanini, C.; Klohe, J. Allgemeines Konzept Living Labs im Ländlichen Raum; Fraunhofer IESE: Kaiserslautern, Germany, 2017.

52. Šūmane, S.; Kunda, I.; Knickel, K.; Strauss, A.; Tisenkopfs, T.; Des Ios Rios, I.; Rivera, M.; Chebach, T.; Ashkenazy, A. Local and Farmers' Knowledge Matters! How Integrating Informal and Formal Knowledge Enhances Sustainable and Resilient Agriculture. J. Rural Stud. 2018, 59, 232-241. [CrossRef]

53. Mulder, I.; Stappers, P.J. Co-Creating in Practice: Results and Challenges. In Proceedings of the IEEE International Technology Management Conference (ITMC), Leiden, The Netherlands, 22-24 June 2009; pp. 1-8.

54. Kobzeva, M.; Knickel, K. "Instead of just Talking We Are actually Doing It!" Initial In-sights into the Use of Living Labs in the EU-funded ROBUST Project; ROBUST: Gloucestershire, UK, 2018.

55. Zardo, P.; Barnett, A.G.; Suzor, N.; Cahill, T. Does Engagement Predict Research Use? An Analysis of the Conversation Annual Survey 2016. PLoS ONE 2018, 13, e0192290. [CrossRef] [PubMed]

56. Barston, D.; Tusting, K. Beyond Communities of Practice: Language Power and Social Context; Cambridge University Press: Cambridge, UK, 2005.

57. Wenger, E. Communities of Practice, Learning, Meaning, and Identity; Cambridge University Press: Cambridge, UK, 1998.

58. Maye, D.; Keech, D.; Matthew, M. Methodological Framework for Case Studies; ROBUST: Gloucestershire, UK, 2018.

59. Obeng, R. An Exploration of the Case Study Methodological Approach through Research and Development. Northeast. Univ. Coll. Prof. Stud. Mass. USA 2015, 1-13. [CrossRef]

60. Flyvbjerg, B. Five Misunderstandings about Case-Study Research. Qual. Inq. 2006, 12, 219-245. [CrossRef]

61. Bakogiannis, E.; Siti, M.; Vassi, A.; Christodoulopoulou, G.; Kyriakidis, C. Case studies and sustainable urban mobility research schemes: A communication channel among researchers and interdisciplinary community groups. Int. J. Serv. Sci. Manag. Eng. 2014, 1, 42-51.

62. Yin, R.K. Introducing the World of Education: A Case Study Reader; Sage Publications: Thousand Oaks, CA, USA, 2005.

63. Thomas, G. A typology for the case study in social science following a review of definition, discourse, and structure. Qual. Inq. 2011, 17, 511-521. [CrossRef]

64. Stake, R.E. The Art of Case Study Research; Sage Publications: Thousand Oaks, CA, USA, 1995.

65. Eisenhardt, K.M. Building theories from case study research. Acad. Manag. Rev. 1989, 14, 532-550. [CrossRef]

66. Stevenson, R. Constructing knowledge of educational practices from case studies. Environ. Educ. Res. 2004, 10, 39-51. [CrossRef]

67. Amt der Steiermärkischen Landesregierung. Kraftfahrzeuge. Available online: https://www.landesentwicklung.steiermark.at/ cms/beitrag/12658772/141979459/ (accessed on 25 September 2020).

68. Interreg Central Europe Project. Status Quo Analysis of Intermodal, ICT, ITS and Smart Governance Mobility Related Solutions in Seven Partner Regions; Interreg Central Europe Project, s.a.: Vienna, Austria. Available online: https://www.interreg-central.eu/ Content.Node/Regional-status-quo-analysis-in-seven-partner-regions-1.pdf (accessed on 18 September 2020).

69. Statistical Office of Republic of Slovenia. Number of Population and Natural Change of Population, Slovenia, Annually. Table ID: 05A210. Available online: https:/ / pxweb.stat.si/SiStatData/pxweb/en/Data/- /05A2010S.px/ (accessed on 10 September 2020).

70. Statistical Office of Republic of Slovenia. Passenger Cars, Buses and Goods Motor Vehicles and First Registrations of Those Vehicles by Type of Drive and Fuel, Slovenia, Annually. Table ID: 2222109. Available online: https://pxweb.stat.si/SiStatData/ pxweb/en/Data/-/2222109S.px/ (accessed on 10 September 2020).

71. Welsh Government. Road Traffic: 2018. Statistics of 2019. Available online: https://gov.wales/road-traffic-2018-html (accessed on 30 September 2020).

72. Regionalmanagement Steirischer Zentralraum. Regionale Entwicklungsstrategie für den Steirischen Zentralraum 2020+; RMSZR: Graz, Austria, 2019. 
73. PLANUM; Fallast Tischler Partner GmbH. Regiotim-Täglich intelligent mobil im Steirischen Zentralraum Phase 1. Available online: https:/ / www.landesentwicklung.steiermark.at/cms/dokumente/12636806_142543737/33729a61/2020_RES_Folder_ final.pdf (accessed on 25 January 2021).

74. HOLDING GRAZ. KombiMo II ist "Kombinierte Mobilität” in Graz. Available online: https:/ /www.holding-graz.at/kombimo. html (accessed on 23 November 2020).

75. Interreg Central Europe. Peripheral Access. Available online: https://www.interreg-central.eu/Content.Node/PeripheralAccess.html (accessed on 30 September 2020).

76. Hart bei Graz. Fahren Voll auf Tim Ab. Available online: https://www.meinbezirk.at/graz-umgebung/c-lokales/fahren-vollauf-tim-ab_a4281981 (accessed on 12 January 2021).

77. Holding Graz. Gewechselt. Geschont. Gespart. Was Tim Geschafft Hat. Ein Bericht. Available online: https://www.quintessenz.or. at/docs/Tim\%20berichtet_2019_komprimiert.pdf (accessed on 12 January 2021).

78. Regionalmanagement Steirischer Zentralraum. Datenauswertung GUSTmobil. ISTmobil GmbH; RMSZR: Graz, Austria, 2020.

79. Voh Boštic, A. Analiza: Kako zanesljiv je ljubljanski sistem za izposojo koles Bicikelj. Available online: https:/ / podcrto.si/analizakako-zanesljiv-je-ljubljanski-sistem-za-izposojo-koles-bicikelj/ (accessed on 29 February 2020).

80. City of Ljubljana (Mestna občina Ljubljana). BicikeLJ Podira Rekorde—6094 Dnevnih Izposoj Kolesa. Available online: https: / / www.ljubljana.si/sl/aktualno/bicikelj-podira-rekorde-6-094-dnevnih-izposoj-kolesa/ (accessed on 29 February 2020).

81. Ploštajner, K.; Ramšak, R.; Vombergar, N. Kolo kot orodje ekološke emancipacije. Časopis za kritiko znanosti 2015, 43, 169-180.

82. Regional Development Agency of Ljubljana Urban Region (RDA LUR). "Prevozi na Klic” na Škofljici. Available online: https: / / rralur.si/novice/prevozi-na-klic-na-skofljici/ (accessed on 10 September 2020).

83. Internal Report of Regional Development Agency of Ljubljana Urban Region, Available from the Regional Development Agency. Available online: https:/ / rralur.si/en/ (accessed on 10 September 2020).

84. Campaign for Better Transport. Buses in Crisis. A Report on Bus Funding Across England and Wales 2010-2016; Campaign for Better Transport: London, UK, 2016. Available online: https://bettertransport.org.uk/sites/default/files/research-files/buses-in-crisis2015.pdf (accessed on 30 September 2020).

85. Monmouthshire Business \& Enterprise. Rural Transport Study: Final Report; Monmouthshire County Council: Monmouthshire, UK, 2018.

86. Tracks. The Future of Rural Bus Services in the UK. Available online: https:/ / bettertransport.org.uk/sites/default/files/researchfiles/The-Future-of-Rural-Bus-Services.pdf (accessed on 30 September 2020).

87. National Assembly for Wales. Inquiry into Loneliness and Isolation. Health, Social Care and Sport Committee. Available online: https: / / www.assembly.wales/laid\%20documents/cr-1d11310/cr-ld11310-e.pdf (accessed on 30 September 2020). 